\title{
INFLUENCE OF ELECTRODE TEMPERATURE ON THE CHARACTERISTICS OF A NON UNIFORM FIELD SYSTEM WITH A BARRIER
}

\author{
M.C. Siddagangappa \\ Department of High Voltage Engineering \\ Indian Institute of Science \\ Bangalore 560 012, India
}

\author{
D.K.Mandal \\ Bharat Heavy Electricals limited \\ Transmission Business Group \\ Lodhi Road, New Delhi 110 003, India
}

\begin{abstract}
Electrode temperature controlled ac corona discharge inception voltages of a non uniform field electrode system and the characteristics change of CIV in the presence of a barrier is investigated. Reduction in the breakdown voltages of the gap for negative standard impulse applications was observed as the point electrode temperature raised upto $200^{\circ} \mathrm{C}$ and the characteristic occurrence was repeated in the presence of press board barrier.
\end{abstract}

\section{INTRODUCTION}

When a composite insulation system of gas and solid is subjected to high electrical stresses, charged particles produced in the localised discharges either penetrates or deposits on the solid dielectrics altering the field distribution. Thus, the reliability and the characteristics of a composite insulation system are controlled by combination of electrode field conditions, gaseous medium and of course on the solid dielectric material used together with surface conditions. Invariably, solid dielectric barriers are used in high voltage switchgear systems, whereas the dielectric barrier discharge is finding application as a source of atmospheric pressure non thermal plasma to be used for environmental pollution control [1]

Important investigation by Van Brunt and co-workers [2] reported on the fundamental characteristics behavior of corona discharges in air influenced by solid dielectric barrier. Awad and Castle [3] have studied the electrode temperature controlled corona currents using a co-axial wire tube geometry. Though, temperature influences the swarm data in synthetic air, systematic breakdown voltage measurements in nearly homogenous field condition do not support the temperature dependence as reported by Zaengl et.al [4], wherein both electrodes and synthetic air were maintained at the same temperature in a confined volume.

The present preliminary investigation was conducted to examine the influence of electrode temperature on the characteristics of composite non uniform field system having a solid insulation barrier.

\section{EXPERIMENTAL DETAILS}

A point and sphere electrodes were mounted on a common axis on an insulator base and the required gap length could be adjusted. The stainless steel point electrode was of $6 \mathrm{~mm}$ dia tapered at one end as a cone forming a tip surface of $1 \mathrm{~mm}$ dia. The copper sphere of $62.5 \mathrm{~mm}$ was connected to the high potential end of the power source. The point electrode terminated to ground via current measuring circuit, and was insulated with a mica tube from a 750 watt a.c. heater. A grounded metal shield was provided between heater and the point electrode to avoid leakage currents due to the heater supply voltage. A temperature controller with a shielded thermocouple sensor attached was used to maintain the electrode tip at specified temperatures with a variation of $\pm 1^{\circ} \mathrm{C}$. The high voltage a.c power was derived from a $230 \mathrm{~V} / 115 \mathrm{kV}, 10 \mathrm{KVA}$, $50 \mathrm{~Hz}$ transformer having a voltage measuring winding ratio of 1:1000. The input to the transformer was controlled by a voltage regulator.

The corona inception currents (CIC) were obtained by measuring the potential drop across $1 \mathrm{k} \Omega$ resistor ( $\pm 1 \%$ tolerance). The voltage drop across the resistor due to the current flowing in the circuit was measured using a broad band $(2 \mathrm{~Hz}$ to $1 \mathrm{MHz})$ millivoltmeter having input impedance of $300 \mathrm{M} \Omega$. The waveform and corona inception voltage (CIV) levels were also observed on an oscilloscope. The CIV recorded are those, relating to the first appearance of minimum detectable gap current $(1 \mu \mathrm{A})$ and of the negative discharge sensed by the measuring system.

The impulse voltages used were obtained by $165 \mathrm{kV}, 1.5 \mathrm{~kJ}, 4$ stage Marx generator. The standard $1.2 / 50 \mu$ s negative impulse voltages were measured by a precision damped capacitance divider coupled to a peak voltmeter and recorded on a surge oscilloscope (Hafeley). Fifty percent breakdown voltages $\left(\mathrm{V}_{50}\right)$ determined by up and down method.

Repeated experiments on the composite insulation system 
revealed that the area of the circular barrier placed perpendicular to the electrode axis have significant effect on CIV levels. However, the CIV data reaches a stabilization when the barrier diameter was two times that of sphere electrode. Further increase in the area of the barrier have had no effect on the corona inception characteristics of the composite insulation system. Finally the experiments were conducted with pressboard barriers of $150 \mathrm{~mm}$ dia and of $1.5 \mathrm{~mm}$ thickness.

\section{RESULTS AND DISCUSSION}

With a simple experimental setup and conventional measuring method adopted, CIV data for point electrode temperatures of 27, 50,100,150 and $200^{\circ} \mathrm{C}$ and for gap distance of 20 , 30 and $40 \mathrm{~mm}$ are shown in figure 1 . The corona inception voltages decreased with increase in point electrode temperature. The discharge currents recorded at inception. were of the same order ( 5 to $7 \mu \mathrm{A}$ ), even when the electrode temperature was at $200^{\circ} \mathrm{C}$, are not shown in the figure. CIV data of a non uniform composite insulation system was obtained for gap lengths of 20,30 and $40 \mathrm{~mm}$ and are plotted in figure 2 ., against press board barrier position measured with reference to the point electrode. The maximum CIV was observed for the barrier positions around the axial centre of the electrode gap and higher than CIV recorded with no barrier. However, when the barrier moves towards any of the electrodes in the system CIV continue to decrease and falls below the value of simple electrode gap. The CIC showed no significant variations for different barrier positions in the gap.

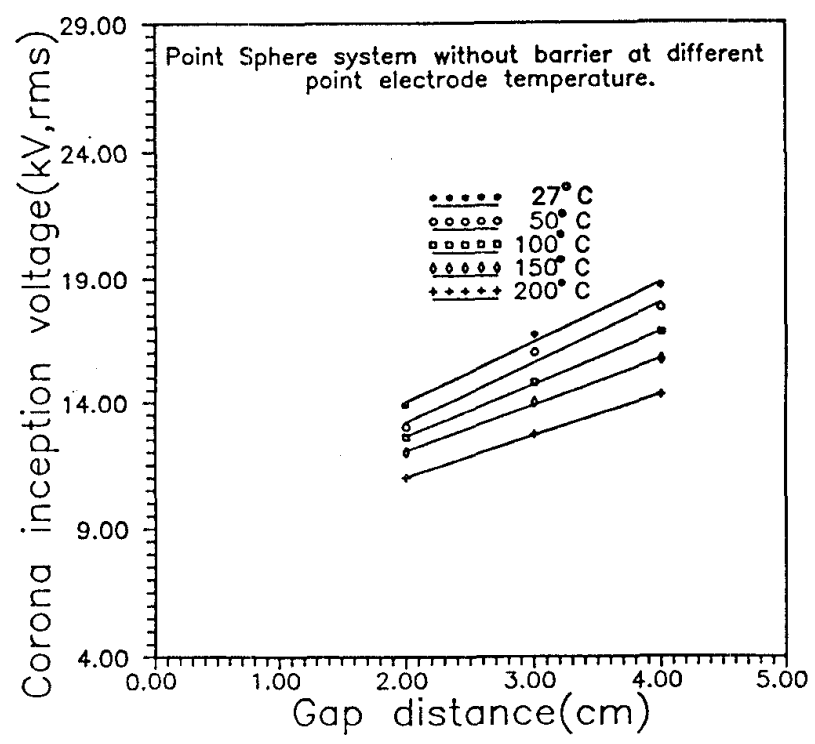

Figure 1. Corona inception voltages as a function of gap length for various point electrode temperatures.
Further, the effect of electrode temperature on CIV of composite insulation was studied by maintaining the point electrode at $50,100,150$ and $200^{\circ} \mathrm{C}$. CIV data for gap lengths 20,30 and $40 \mathrm{~mm}$ with constant electrode temperature of 200 ${ }^{\circ} \mathrm{C}$ are plotted in figure 3 . The reduced CIV values of heated pointed electrode follow the same trend of the data obtained for studies at room temperature in the presence of a barrier which is shown for comparison in the figure. The investigations were also conducted to assess the change in breakdown strength with electrode temperature, by applying standard negative impulse voltages to the sphere electrode. Negative impulse breakdown data $\left(\mathrm{V}_{50}\right)$ obtained for various gap distances with electrode temperatures in the range of 20 to $200^{\circ} \mathrm{C}$ , are plotted in figure 4. As is evident from the figure, the negative impulse breakdown strength has fallen by about an average of $25 \%$ for the gaps studied when the temperature of the point electrode reaches $200^{\circ} \mathrm{C}$.

Impulse breakdown experiments were extended for the composite system and for different barrier positions. The breakdown of the system if occurred was always through the centre of the barrier and no extraneous breakdown was observed. After each impulse breakdown of the gap, barrier was replaced by new one. The data for $10 \mathrm{~mm}$ gap length is plotted in figure 5 for various barrier positions and for constant electrode temperatures. Similar characteristics were observed for 20 to 30 $\mathrm{mm}$ gap lengths investigated. By comparing the data of figures 3 and 4 , calculated relative breakdown strength of the gap in the presence of a barrier is always higher and is consistent with the earlier studies [5].

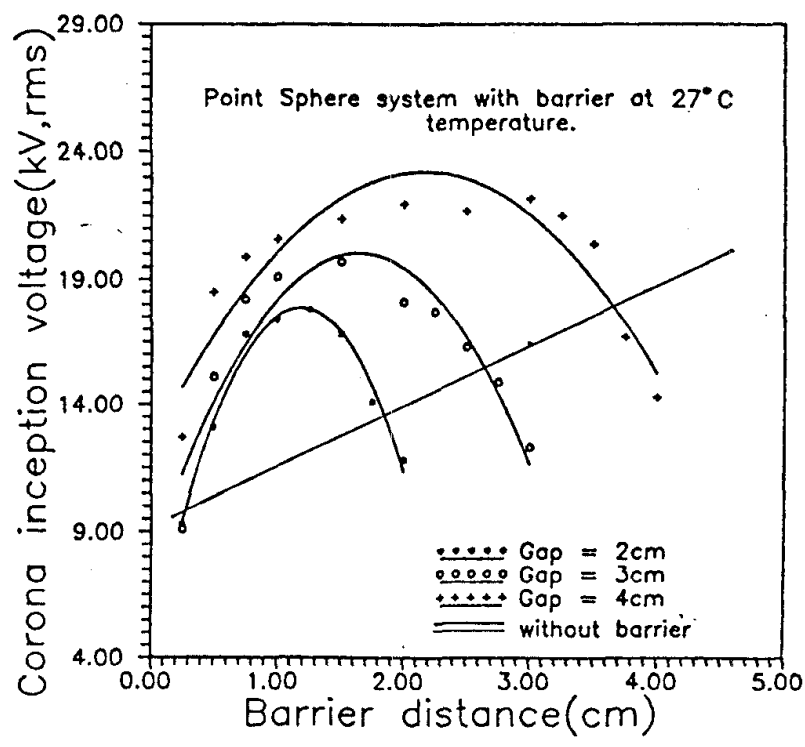

Figure 2. Corona inception voltages as a function of barrier distance with reference to the point electrode. 


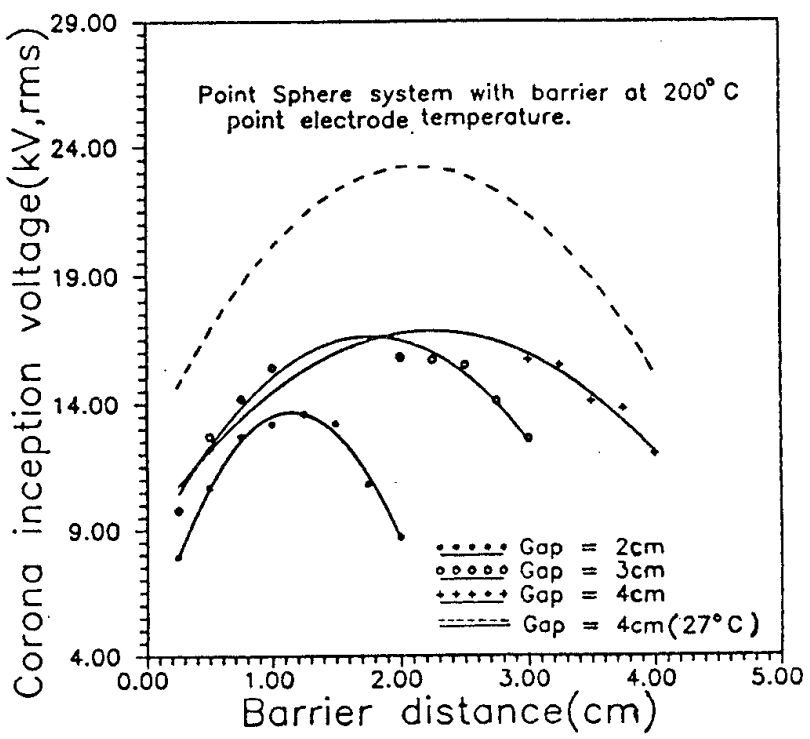

Figure 3. Corona inception voltages as a function of barrier distance at different point electrode temperatures.

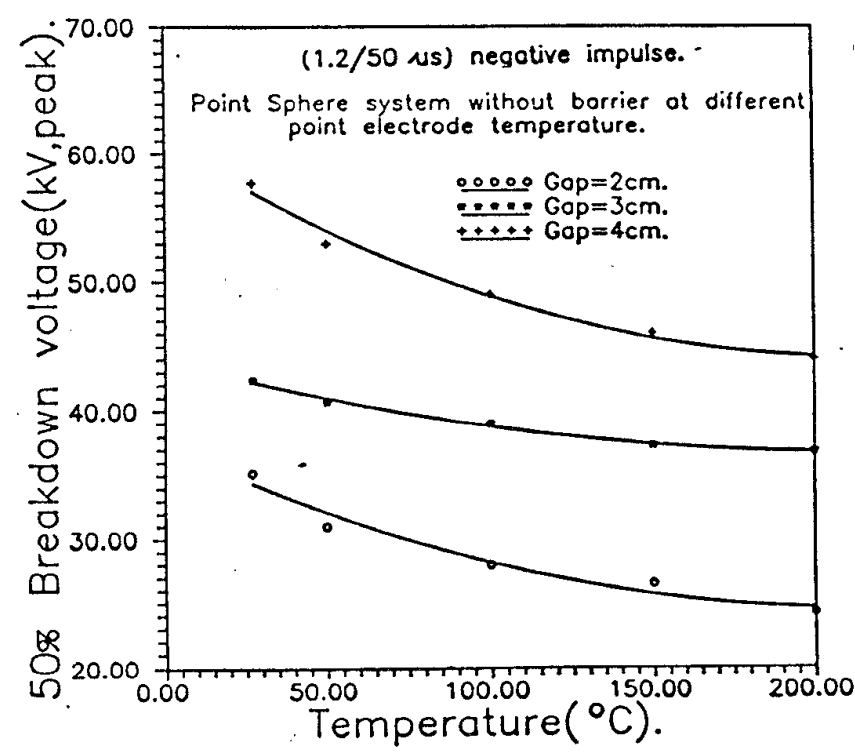

Figure 4. Fifty percent breakdown voltages as a function of point electrode temperatures.

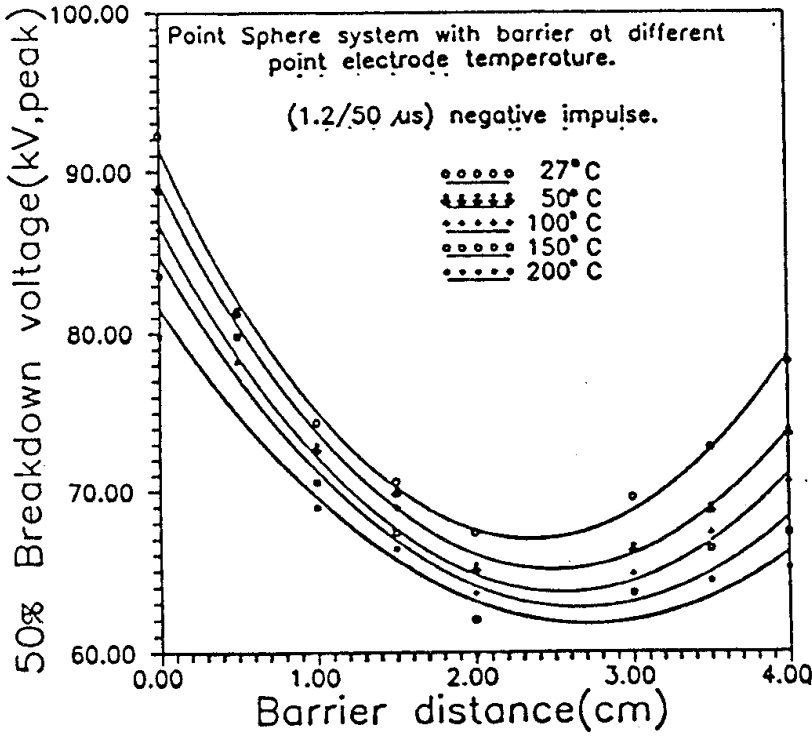

Figure 5. Fifty percent breakdown voltages as a function of barrier position for various point electrode temperatures.

\section{CONCLUSIONS}

In a non uniform field system, higher electrode temperature causes a decrease in the magnitude of CIV while there are no appreciable changes in CIC. In the composite insulation system, CIV data is controlled by electrode temperature and as well by the presence of a barrier. Relative impulse breakdown strength of the insulation system is observed to be reduced as a function of temperature, indicating a major role played by the thermal conditions of the electrode.

The classic answer for the temperature dependent CIV data is the change in air density factor $\delta[6]$, because of thermal gradient just close to the surface of the point electrode, which constitutes a small percentage of gaseous insulation volume. Early work of Alston [7] indicated pronounced effect of hot spot in uniform fields reducing dc flashover values in air. In light of the recent studies by Zaengal and co workers [4] revealing no temperature dependence of homogeneous field breakdown in synthetic air, reasonable explanation is yet to be evolved for electrode temperature dependence on the dielectric system behaviour. 


\section{ACKNOWLEDGMENTS}

The authors wish to thank Mr. B.Nageshwar Rao,Mr. Jagannatha and Mr. Rajashekar for the timely help received in this work.

\section{REFERENCES}

1. Bijan Pashie, Shirshak K Dhali and Frank I Honea. "Electrical characteristics of a coaxial dielectric barrier discharge". J. Phys. D: Appl. Phys. Vol.2, 1994, pp. 2107 -2110

2. Van Brunt, R. J, Misakian, M, Kulkarni. S. V. and Lakdawala. V.K. "Influence of a Dielectric barrier on the stochastic behaviour of trichel -pulse corona". IEEE Trans. E.I. Vol.26 No.3, June 1991, pp- 405-415.

3. Awad, M.B and Castle, G.S.P. " Breakdown streamers in coronas with heated Discharge Electrode". IEEE Trans E.I. Vol.2, No.3, June 1977, pp. 234-236.

4. Zaengal, W.S, Yimvuthikul and Friedrich, G. "The Temperature Dependence of Homogeneous Field Breakdowns in Synthetic Air". IEEE Trans. EI. Vol.26, No.3, June 1991, pp. 380 -390.

5. Teruya Kouno. “ Breakdown of composite Dielectrics: The Barrier effect”. IEEE Trans EI. Vol. 15, No.3, June 1980, pp. 259 263

6. Cobine, J. D. Gaseous Conductors. Dover Publication. N. Y. 1958, p.255

7. Alston, L.L. "High-Temperature effects on Flashover in Air". Proceedings IEE, Vol. 105, Pt A, No.24, December 1958, pp. 549 $-553$ 